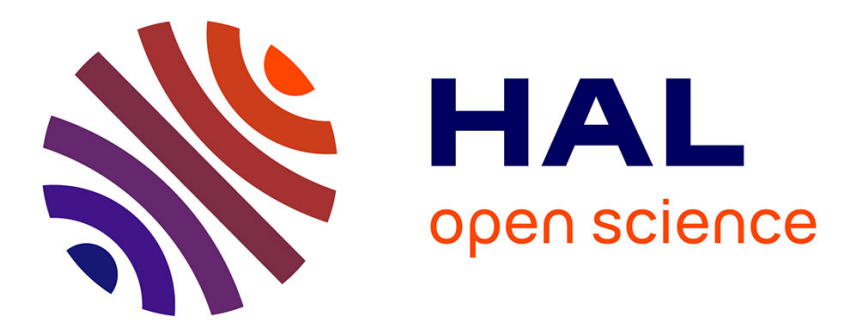

\title{
Psychotropic drug use in community-dwelling elderly people-characteristics of persistent and incident users
}

Maria Rikala, Maarit Jaana Korhonen, Raimo Sulkava, Sirpa Hartikainen

\section{To cite this version:}

Maria Rikala, Maarit Jaana Korhonen, Raimo Sulkava, Sirpa Hartikainen. Psychotropic drug use in community-dwelling elderly people-characteristics of persistent and incident users. European Journal of Clinical Pharmacology, 2011, 67 (7), pp.731-739. 10.1007/s00228-011-0996-5 . hal-00666480

\section{HAL Id: hal-00666480 \\ https://hal.science/hal-00666480}

Submitted on 5 Feb 2012

HAL is a multi-disciplinary open access archive for the deposit and dissemination of scientific research documents, whether they are published or not. The documents may come from teaching and research institutions in France or abroad, or from public or private research centers.
L'archive ouverte pluridisciplinaire HAL, est destinée au dépôt et à la diffusion de documents scientifiques de niveau recherche, publiés ou non, émanant des établissements d'enseignement et de recherche français ou étrangers, des laboratoires publics ou privés. 
1 Title: Psychotropic drug use in community-dwelling elderly people - characteristics of

3

4

Authors:

5 Maria Rikala ${ }^{1,2}$, Maarit Jaana Korhonen ${ }^{3}$, Raimo Sulkava ${ }^{4,5}$, Sirpa Hartikainen ${ }^{1,6,7}$

$6{ }^{1}$ Kuopio Research Centre of Geriatric Care, University of Eastern Finland, Kuopio, Finland

$7 \quad{ }^{2}$ School of Pharmacy/Social Pharmacy, University of Eastern Finland, Kuopio, Finland

$8{ }^{3}$ Department of Pharmacology, Drug Development and Therapeutics, University of Turku,

9 Turku, Finland

$10{ }^{4}$ Institute of Public Health and Clinical Nutrition, University of Eastern Finland, Kuopio,

11 Finland

$12{ }^{5}$ Department of Neurology, Kuopio University Hospital, Kuopio, Finland

$13{ }^{6}$ School of Pharmacy/Clinical Pharmacology and Geriatric Pharmacotherapy, University of 14 Eastern Finland, Kuopio, Finland

${ }^{7}$ Leppävirta Health Centre, Leppävirta, Finland

\section{Corresponding author:}

Maria Rikala

School of Pharmacy, University of Eastern Finland, PO Box 1627, 70211 Kuopio, Finland,

Phone +358 40 3553125, Fax +358 17 162242, e-mail: maria.rikala@uef.fi

WORDS: 3099

KEY WORDS: psychotropic drugs, persistent use, incidence, elderly 


\section{ABSTRACT}

(

PURPOSE This prospective cohort study aimed to analyze psychotropic drug use in community-dwelling elderly people over a 3-year period and characterize persons most susceptible to persistent and incident use.

METHODS Data on demographics, health status, cognition, functional capacity and drug use were gathered by interviews at baseline (2004) and in three follow-ups (2005-2007) in a population-based sample of 700 community-dwelling people aged $\geq 75$ years. Characteristics associated with persistent and incident use were identified using Cox proportional-hazards regression.

RESULTS At baseline, 38\% $(n=269)$ of the participants used psychotropic drugs. Of them, $60 \%(n=162)$ reported use in all three follow-ups, whereas $22 \%(n=59)$ discontinued use. Among the baseline users of antipsychotics $(n=40)$, antidepressants $(n=83)$ and benzodiazepines $(n=219)$, respectively $43 \%, 51 \%$ and $55 \%$ reported use in all three followups. The characteristics associated with persistent use of psychotropic drugs included concomitant use of psychotropic drugs, regular use of psychotropic drugs, increasing age and good self-rated health. Among the baseline nonusers of psychotropic drugs ( $n=431), 20 \%$ $(n=88)$ initiated use during the follow-up. Incident use of psychotropic drugs was associated with increasing GDS scores, MMSE score $\leq 24$, number of visits to physician $\geq 6$, moderate/poor self-rated health and moderate/poor life satisfaction.

CONCLUSIONS Psychotropic drugs, particularly benzodiazepines, are frequently used for extended periods in community-dwelling people aged $\geq 75$ years. Persons with multiple psychotropic drugs and regular pattern of use are most susceptible to persistent use.

Characteristics associated with incident use include depressive symptoms, cognitive decline and poor general health. 
3 Psychotropic drugs are extensively used in the elderly [1-3]. In Finland, more than one-third

4 of community-dwelling people aged $\geq 75$ years use at least one psychotropic drug [2]. A major

5 concern surrounding psychotropic drug use is the potential for unfavorable outcomes.

6 Specifically, use of benzodiazepines, antidepressants and antipsychotics has been associated

7 with an increased risk of falls $[4,5]$. Other concerns related to benzodiazepine use include

8 dependence [6] and cognitive decline [7]. Moreover, use of antipsychotics may increase

9 mortality among elderly people with dementia [8, 9].

In general, psychotropic drugs are recommended to be used for a limited period of time in the elderly. Specifically, benzodiazepines should not be used for longer than two or four weeks [6] and antidepressant use should be discontinued 12 months after achieving remission from depression [10]. Furthermore, periodic attempts to reduce or discontinue antipsychotic use are suggested in people with dementia [11]. However, extended periods of psychotropic drug use are indicated in certain psychiatric disorders, such as schizophrenia [12] and recurrent major depression [10].

Although the guidelines recommend limited duration, several studies indicate that psychotropic drugs are frequently used for extended periods, particularly among elderly people [13-16]. The occurrence of use deemed as persistent ranges from $4.5 \%$ to $21.5 \%$ in general elderly population [17-24] and from $39 \%$ to $70 \%$ in elderly users of psychotropic drugs $[17,20,21,23-25]$. Besides differences in the study populations and drugs considered, heterogeneity may result from variations in the definition (from 90 days up to 6 years) and the 
1 7

.

method of assessment of persistent use (retrospective self-reports, consecutive interviews, pharmacy claims databases).

Identification of characteristics associated with persistent use of psychotropic drugs would aid health care professionals to recognize high-risk patients. Since new users frequently end up as persistent users [26], also characteristics related to incident use need to be specified. Although several studies have investigated the occurrence and determinants of persistent and incident use of psychotropic drugs among elderly people [17-28], few considered other drugs than benzodiazepines $[17,24]$ or focused on people aged $\geq 75$ years [19]. In addition, the majority of the studies were conducted in 1980s or in early 1990s [17-21, 27, 28]. Furthermore, some follow-up studies analyzed only those surviving until the end of the follow-up [19, 24], potentially excluding those with the highest risk for persistent and incident use. This prospective cohort study aimed to analyze psychotropic drug use over a 3-year period in community-dwelling people aged $\geq 75$ years. In addition, persons most susceptible to persistent and incident use were characterized. 
METHODS

\section{Study population}

(4)

The current study was based on the data from the population based GeMS (Geriatric Multidisciplinary Strategy for the Good Care for the Elderly) intervention study. Initially, a random sample of 1000 persons aged $\geq 75$ years (born before 1 November 1928) living in the City of Kuopio, Finland was selected from the census data of the City of Kuopio. These persons were randomly assigned to intervention $(n=500)$ and control $(n=500)$ groups. The baseline examination was performed in 2004, with follow-ups in three consecutive years in 2005, 2006 and 2007. Of the initial sample, 162 refused, two had moved, 81 lived in institutional settings and 55 died before baseline. The remaining 700 community-dwelling participants were included in the analysis. During the study period, 119 participants were lost to follow-up because of death $(n=100)$, refusal $(n=17)$, moving $(n=1)$ or not being able to contact $(n=1)$.

\section{Data collection}

The study protocol has been described more detailed elsewhere [29]. Briefly, the participants of the intervention group underwent a Comprehensive Geriatric Assessment (CGA) at the baseline (2004) and in the 1-year (2005) and 2-year (2006) follow-ups. The CGA included a clinical examination, medication assessment and interventions to improve nutritional state and functional capacity by a team of two physicians (trainees in geriatrics), three study nurses, two physiotherapists and a nutritionist. In addition to the CGA, the participants in the intervention and control groups were interviewed annually (2004-2007) by three study nurses 
to assess demographic characteristics, health status, cognition, functional capacity and drug use.

The study nurses interviewed the participants either in a municipal health center or at participants' homes, using a structured questionnaire. The Mini-Mental State Examination (MMSE) was used to assess cognitive performance [30]. The Geriatric Depression Scale (GDS15) was employed as a screening instrument for depressive symptoms [31]. Limitations in instrumental activities of daily living (IADL) were screened by the scale developed by Lawton and Brody [32]. Years of education, living situation (alone, with someone), self-rated health (good, fairly good, moderate, fairly poor, poor), self-rated life satisfaction (very satisfied, satisfied, unsatisfied, very unsatisfied) and the number of visits to physician during the year preceding the baseline interview were self-reported by the participants. Information on history of psychosis was based on the medical records of the municipal health center and participants own report. If the participant was unable to answer (e.g. due to dementia), a caregiver or home nursing staff responded instead.

During study nurses' annual interviews (2004-2007), the participants were asked to specify all the prescription and over-the-counter drugs they were currently taking. Each time the information was confirmed from prescriptions, drug packages and medical records of the municipal health center. Drugs used daily, several times a week or at regular intervals (e.g. long-acting injectable antipsychotics) were defined as regular drugs, while other drugs were considered to be "as needed" drugs. All drugs were coded according to the Anatomical Therapeutic Chemical (ATC) classification system recommended by World Health Organization [33]. 


\section{Psychotropic drugs}

2

3 In the current study, psychotropic drugs were defined as antipsychotics (N05A),

4 benzodiazepines (N05B, N05C excluding buspirone, hydroxyzine, valerian and melatonin)

5 and antidepressants (N06A, N06CA01) according to the ATC-classification [33]. A user of a

6 psychotropic drug refers to a participant who was using at least one psychotropic drug either

7 regularly or "as needed" based on the data collected by the study nurses.

\section{Statistical analyses}

Characteristics of users and nonusers of psychotropic drugs at baseline were compared using the Pearson $\chi^{2}$-test for categorical variables and the Mann-Whitney U test for continuous variables. Baseline characteristics associated with persistent (event: discontinuation) and incident use of psychotropic drugs were identified among 700 community-dwelling participants using Cox proportional-hazards regression. Discontinuation occurred when a baseline user did not report any use of psychotropic drugs in a follow-up, whereas initiation occurred when a baseline nonuser reported any use of psychotropic drugs in a follow-up. Survival time was censored at the end of 2007 for participants who did not experience the event during the study period. For the participants who were lost to follow-up without experiencing the event ( $n=48$ in discontinuation analysis and $n=55$ in initiation analysis), the survival time was censored at the end of the loss year. The most important reason for loss to follow-up was death in both analyses (88\% and $78 \%$ of those lost to follow-up respectively). Psychotropic drugs were analyzed together because of the high frequency of concomitant use (e.g. benzodiazepine and antidepressant) and switching between therapeutic categories (e.g. from benzodiazepine to antipsychotic). 
1 The baseline characteristics included in the Cox proportional-hazards regression analyses are

2 presented in the Table 1 . A threshold of $\leq 24$ for MMSE scores was used to define cognitive decline and a threshold of $\leq 6$ for IADL scores to indicate impairment. Self-rated health was dichotomized into good (includes good and fairly good) and moderate/poor (includes moderate, fairly poor and poor). Self-rated life satisfaction was divided into excellent (includes very satisfied) and moderate/poor (includes satisfied, unsatisfied and very unsatisfied). The number of non-psychotropic drugs included both regularly and "as needed" taken drugs. Age and GDS15 scores were treated as continuous variables. History of psychosis was not included in the analyses because of the low number of participants affected $(n=20)$. The participants of the intervention and control groups were analyzed together because the group assignment was not associated with discontinuation of psychotropic drug use $(\mathrm{HR}=1.09 ; 95 \% \mathrm{CI} 0.65-1.82)$, nor with the initiation of use $(\mathrm{HR}=0.90 ; 95 \%$ CI 0.59 1.36). In addition, the intervention had minor effects on the prevalence of use of antipsychotics, benzodiazepines and antidepressants [29]. Nevertheless, group assignment was included in the models as a design variable.

Both crude and adjusted Cox proportional-hazards regression analyses were performed. The proportional-hazards assumption for each categorical variable was evaluated by comparing adjusted survival curves between categories. The participants missing data on the chosen variables were excluded from the analyses except for GDS15 scores, the values for which were imputed with the mean value (2) for the whole study population. Data management and statistical analyses were performed using Statistical Package for Social Sciences (SPSS), version 14.0 (SPSS Inc., Chicago, USA). 


\section{Ethical issues}

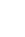

Written informed consent was obtained from the participants or their family members or their caregivers. The study protocol was approved by the Research Ethics Committee of the Hospital District of Northern Savo as required by the Finnish legislation.

\section{RESULTS}

\section{Psychotropic drug use at baseline}

At baseline, $38 \%(n=269)$ of the community-dwelling participants used at least one psychotropic drug. The majority of them $(68 \%, \mathrm{n}=183)$ were using psychotropic drugs on a regular basis. Benzodiazepines were the most commonly used category $(31 \%, \mathrm{n}=219)$, followed by antidepressants $(12 \%, n=83)$ and antipsychotics $(6 \%, n=40)$. Of the users of psychotropic drugs, every third $(28 \%, \mathrm{n}=76)$ used at least two psychotropic drugs.

Compared with the nonusers, the users of psychotropic drugs were older, more commonly women and lived more commonly alone (Table 1). In addition, the users and nonusers differed in terms of health status, cognition, functional capacity and drug use. Of the users of psychotropic drugs, 19 had a history of psychosis of the following types: schizophrenic $(n=6)$, paranoid $(n=7)$, depressive $(n=4)$, reactive $(n=1)$ and unclassified $(n=1)$. 
3 Of the baseline users of psychotropic drugs $(n=269), 60 \%(n=162)$ reported use in all three

4 follow-ups (Table 2). The majority of these persistent users had a regular pattern of use at 5 baseline $(n=120)$ and in each three follow-ups ( $n=126, n=130$ and $n=135$ respectively). Over 6 half $(n=85)$ of the persistent users reported use of at least two therapeutic categories during 7 the follow-up either in the same year (concomitant use) or in different years (switch between therapeutic categories). Of the persistent users of psychotropic drugs, $8 \%(n=13)$ had a history of psychosis, $14 \%(n=22)$ had GDS15 scores $\geq 5$ and 27\% $(n=43)$ had MMSE scores $\leq 24$.

When the baseline users of antipsychotics, antidepressants and benzodiazepines were analyzed separately, $43 \%, 51 \%$ and $55 \%$ respectively, reported use in all three follow-ups (Table 3).

Of the baseline users of psychotropic drugs $(n=269), 22 \%(n=59)$ discontinued all psychotropic drugs during the follow-up (Table 2). In adjusted Cox proportional-hazards regression analysis, oldest persons, users of at least two psychotropic drugs, regular users of psychotropic drugs and people with good self-rated health were less likely to discontinue use (Table 4), representing the characteristics associated with persistent use. Hazard ratios (HR) were materially the same (differed less than $10 \%$ from the reported HRs) after removing the variables number of psychotropic drugs and pattern of psychotropic drug use from the model, except for education ( $\mathrm{HR}=1.36$; 95\% CI 0.77-2.41), number of non-psychotropic drugs $\geq 9$ $(\mathrm{HR}=1.13 ; 95 \% \mathrm{CI} 0.61-2.08)$, MMSE scores $\leq 24(\mathrm{HR}=0.96 ; 95 \% \mathrm{CI} 0.44-2.09)$ and IADL scores $\leq 6(\mathrm{HR}=0.85 ; 95 \%$ CI $0.42-1.72)$. 
3 Among the baseline nonusers of psychotropic drugs $(n=431), 20 \%(n=88)$ initiated psychotropic drug use during the follow-up (Table 2). Of the initiated drugs, the majority were benzodiazepines $(n=44)$, followed by antidepressants $(n=22)$ and antipsychotics $(n=8)$. In addition, 14 participants initiated psychotropic drugs at least from two therapeutic categories (e.g. benzodiazepine and antipsychotic). When the baseline nonusers of antipsychotics, antidepressants and benzodiazepines were analyzed separately, $7 \%, 10 \%$ and $17 \%$ respectively, initiated use during the follow-up (Table 3).

In adjusted Cox proportional-hazards regression analysis, characteristics associated with incident use of psychotropic drugs included increasing GDS15 scores, MMSE score $\leq 24$, number of visits to physician $\geq 6$, moderate/poor self-rated health, and moderate/poor life satisfaction (Table 4).

\section{DISCUSSION}

The current study found a high prevalence of psychotropic drug use in community-dwelling people aged $\geq 75$ years. Despite increasing awareness of potential adverse effects and the guidelines recommending limited duration, psychotropic drugs were frequently used for extended periods. Specifically, $60 \%$ of the baseline users of psychotropic drugs reported use in three following years. In addition, every fifth baseline nonuser initiated psychotropic drug use during the study period, the majority of them reporting use also in the next follow-up. 
1 Extended periods of psychotropic drug use are indicated in certain psychiatric disorders.

2 Precisely, life-long antipsychotic therapy is suggested for patients with schizophrenia and

delusional disorder [12]. At least three years of antidepressant therapy is recommended for patients with recurrent major depression [10]. In addition, extended periods of antidepressant therapy may be necessary to prevent recurrence among patients with panic disorder, generalized anxiety disorder or obsessive compulsive disorder [34, 35]. However, persistent use of psychotropic drugs consisted more of benzodiazepines than antipsychotics and antidepressants. Specifically, every fifth community-dwelling participant used benzodiazepines during the whole study period. This is of concern since benzodiazepines should not be used for longer than two or four weeks in elderly people, because of adverse effects, dependency and limited efficacy in continuous use [6].

Persistent use of psychotropic drugs was specifically associated with use of at least two psychotropic drugs and regular pattern of use. The hazard ratios were materially the same after adjusting for several factors reflecting poor mental and general health, suggesting that the associations were not confounded by participants' health status. Moreover, the findings are consistent with previous research. Precisely, extended periods of benzodiazepine use have been reported among people with more than one benzodiazepine and among people with frequent/daily pattern of use $[14,36]$. Therefore, risk for persistent use needs to be considered before prescribing an additional psychotropic drug to an elderly person. Moreover, recommendations to avoid regular use of benzodiazepines [6] should be strongly emphasized when aiming to decrease the risk for persistent use.

Consistent with the findings of previous studies [17, 24, 27, 28], people with depressive symptoms were more likely to initiate psychotropic drug use. In addition, incident use was 
associated with lower MMSE scores, which may largely explain the high prevalence of psychotropic drug use among elderly people with dementia [2, 3]. Other characteristics associated with incident use included frequent visits to physician, moderate/poor self-rated health and moderate/poor life-satisfaction, suggesting that initiation of psychotropic drugs is also related to physical morbidity, non-specific symptoms and drug seeking behavior. However, these associations may involve residual confounding by some unmeasured conditions, such as insomnia and anxiety.

In contrast to previous research, female gender was not related to persistent $[19,22,25]$ or incident use [24, 27, 28] of psychotropic drugs. Conflicting findings may result from differences in drugs considered and participants' age, the majority of the previous studies focusing on benzodiazepines and people aged $\geq 65$ years. In addition, some follow-up studies analyzed only those surviving until the end of the follow-up [19, 24], potentially leading to over-representation of healthy men in a study population. Furthermore, some studies compared persistent users with never users [19, 23], and therefore their results may reflect determinants of use in general, rather than persistent use. In fact, a number of studies have detected that female gender has minor influence on duration of psychotropic drug use among prevalent users $[17,20,24]$, supporting the findings of the current study.

Besides characteristics considered here, psychotropic drug use may be related to health system characteristics. For example, both incident and persistent use of benzodiazepines has been associated with a high number of prescribing physicians $[22,28]$. The finding could partly explain the frequency of persistent use in Finland, where many different physicians are typically involved in each patient's care. In Finland, it is also common that physicians renew psychotropic prescriptions without meeting the patient [37]. Persistent use of psychotropic 
drugs may also arise from patient attitudes. Negative perceptions against discontinuation are typically attributed to fear of recurrence, feeling of being unable to manage without, and underestimation of potential adverse effects [38-40]. On the other hand, primary care physicians may be pessimistic about successful discontinuation and encounter multiple barriers when trying to interfere in a patient's benzodiazepine use [41].

\section{Methodological considerations}

The annually collected data offered a great opportunity to prospectively analyze longitudinal patterns of psychotropic drug use at an individual level. Furthermore, the self-reported data on drug use can be considered valid since the information was confirmed from the prescriptions, drug packages and medical records. In addition, the self-reported data was in agreement with the information extracted from the Finnish Prescription Register (includes reimbursable drugs dispensed in the Finnish community pharmacies) with $\kappa$ values of 0.84 for antipsychotics, 0.88 for antidepressants and 0.70 for benzodiazepines [42]. A further advantage of the study was the fact that not only the survivors, but also those who were lost to follow-up during the study period were included in the analyses.

The study has some limitations. To begin with, the study may have overestimated the occurrence of persistent use (if a participant had a long gap in psychotropic drug use between the follow-ups) and underestimated the occurrence of both persistent use (if a participant happened to have a gap in psychotropic drug use at the time of the follow-up) and incident use (if a participant used psychotropic drug between the follow-ups). The study was further limited by the fact that at the beginning of the follow-up the sample of psychotropic drug users was a mixture of short-term and long-term users. Therefore, the characteristics of 
1

persistent users identified in this study may differ from those identified in a sample of new users $[15,26]$.

(3)

Some additional limitations need to be considered regarding the Cox proportional-hazards regression analyses. The study could not take into consideration some potential characteristics of persistent and incident users, such as insomnia and anxiety. In addition, the study used only baseline measurements for time-dependent variables. This may have biased the associations for variables with a tendency to vary over time, such as self-rated health and self-rated life satisfaction. Nevertheless, use of time-dependent Cox proportional-hazards regression was not considered appropriate because the potential variation in time-dependent variables may be affected by other variables included in the analyses [43].

\section{CONCLUSIONS}

Psychotropic drugs, particularly benzodiazepines, are frequently used for extended periods in community-dwelling people aged $\geq 75$ years. Persons with multiple psychotropic drugs and regular pattern of use are most susceptible to persistent use. Characteristics associated with incident use include depressive symptoms, cognitive decline and poor general health. Further research is needed to evaluate whether the characteristics of persistent and incident users vary between antipsychotics, antidepressants and benzodiazepines. 


\section{CONFLICTS OF INTEREST}

2

3 The authors declare that they have no conflicts of interest

4

5

\section{ACKNOWLEDGEMENTS}

6

7 The GeMS Study was funded by the Social Insurance Institution of Finland and City of

8 Kuopio, Finland. In addition, financial support was obtained from the Ageing, Well-being and

9 Technology Graduate School, University of Jyväskylä, Finland. The sponsors played no role

10 in the design of the GeMS Study or the preparation of this manuscript. The authors are

11 grateful to research secretary Päivi Heikura and to statistician Piia Lavikainen for their assistance with data management. 
2

3

\section{REFERENCES}

(n)

1. Aparasu RR, Mort JR, Brandt H (2003) Psychotropic prescription use by communitydwelling elderly in the United States. J Am Geriatr Soc 51:671-677

2. Hartikainen S, Rahkonen T, Kautiainen H, Sulkava R (2003) Use of psychotropics among home-dwelling nondemented and demented elderly. Int J Geriatr Psychiatry 18: $1135-1141$

3. Guthrie B, Clark SA, McCowan C (2010) The burden of psychotropic drug prescribing in people with dementia: a population database study. Age Ageing 39: 637-642

4. Hartikainen S, Lönnroos E, Louhivuori K (2007) Medication as a risk factor for falls: critical systematic review. J Gerontol A Biol Sci Med Sci 62: 1172-1181

5. Woolcott JC, Richardson KJ, Wiens MO et al (2009) Meta-analysis of the impact of 9 medication classes on falls in elderly persons. Arch Intern Med 169: 1952-1960

6. Ashton $\mathrm{H}$ (2005) The diagnosis and management of benzodiazepine dependence. Curr Opin Psychiatry 18: 249-255

7. Glass J, Lanctôt KL, Herrmann N, Sproule BA, Busto UE (2005) Sedative hypnotics in older people with insomnia: meta-analysis of risks and benefits. BMJ 19: 331, 1169

8. Gill SS, Bronskill SE, Normand SL et al (2007) Antipsychotic Drug Use and Mortality in Older Adults with Dementia. Ann Intern Med 146: 775-786

9. Ballard C, Hanney ML, Theodoulou M et al (2009) The dementia antipsychotic withdrawal trial (DART-AD): long-term follow-up of a randomised placebocontrolled trial. Lancet Neurol 8:151-157 
1 10. Alexopoulos GS, Katz IR, Reynolds CF 3rd, Carpenter D, Docherty JP, Ross RW (2001) Pharmacotherapy of depression in older patients: A summary of the expert consensus guidelines. J Psychiatr Pract 7: 361-376

11. American Psychiatric Association (2007) Practice guideline for the treatment of patients with Alzheimer's disease and other dementias. 2nd ed. http://www.psychiatryonline.com/pracGuide/PracticePDFs/AlzPG101007.pdf. Accessed 4 January 2011

12. Alexopoulos GS, Streim J, Carpenter D, Docherty JP; Expert Consensus Panel for Using Antipsychotic Drugs in Older Patients (2004) Using antipsychotic drugs in older patients. J Clin Psychiatry 65: Suppl 2, 5-99

13. Simon GE, VonKorff M, Barlow W, Pabiniak C, Wagner E (1996) Predictors of chronic benzodiazepine use in a health maintenance organization sample. J Clin Epidemiol 49:1067-1073

14. Isacson D (1997) Long-term benzodiazepine use: factors of importance and the development of individual use patterns over time - a 13-year follow-up in a Swedish community. Soc Sci Med 44: 1871-1880

15. Fang SY, Chen CY, Chang IS, Wu EC, Chang CM, Lin KM (2009) Predictors of the incidence and discontinuation of long-term use of benzodiazepines: a populationbased study. Drug Alcohol Depend 104: 140-146

16. Cunningham CM, Hanley GE, Morgan S (2010) Patterns in the use of benzodiazepines in British Columbia: examining the impact of increasing research and guideline cautions against long-term use. Health Policy 97: 122-129

17. Dealberto MJ, Seeman T, McAvay GJ, Berkman L (1997) Factors related to current and subsequent psychotropic drug use in an elderly cohort. J Clin Epidemiol 50: 357364 
1 18. Egan M, Moride Y, Wolfson C, Monette J (2000) Long-term continuous use of benzodiazepines by older adults in Quebec: prevalence, incidence, and risk factors. $\mathbf{J}$ Am Geriatr Soc 48: 811-816

19. Jorm AF, Grayson D, Creasey H, Waite L, Broe GA (2000) Long-term benzodiazepine use by elderly people living in the community. Aust N Z J Public Health 24: 7-10

20. Fourrier A, Letenneur L, Dartiques JF, Moore N, Bégaud B (2001) Benzodiazepine use in an elderly community-dwelling population. Characteristics of users and factors associated with subsequent use. Eur J Clin Pharmacol 57: 419-425

21. Gray SL, Eggen AE, Blough D, Buchner D, LaCroix AZ (2003) Benzodiazepine use in older adults enrolled in a health maintenance organization. Am J Geriatr Psychiatry 11: $568-576$

22. Fortin D, Préville M, Ducharme C et al (2007) Factors associated with long-term benzodiazepine use among elderly women and men in Quebec. J Women Aging 19: $37-52$

23. Alvarenga JM, Loyola Filho AI, Firmo JO, Lima-Costa MF, Uchoa E (2008) Prevalence and sociodemographic characteristics associated with benzodiazepines use among community dwelling older adults: the Bambuí Health and Aging Study (BHAS). Rev Bras Psiquiatr 30: 7-11

24. Soudry A, Dufouil C, Ratchie K, Dartiques JF, Tzourio C, Alpérovitch A (2008) Factors associated with changes in antidepressant use in a community-dwelling elderly cohort: the Three-City Study. Eur J Clin Pharmacol 64: 51-59

25. Stowell KR, Chang CC, Bilt J, Stoehr GP, Ganguli M (2008) Sustained benzodiazepines use in a community sample of older adults. J Am Geriatr Soc 56: $2285-2291$ 
26. Luijendijk HJ, Tiemeier H, Hofman A, Heeringa J, Stricker BH (2008) Determinants of chronic benzodiazepine use in the elderly: a longitudinal study. Br J Clin Pharmacol 65: 593-599

27. Lechevallier-Michel N, Berr C, Fourrier-Réglat A (2005) Incidence and characteristics of benzodiazepine use in an elderly cohort: the EVA study. Therapie 60: 561-566

28. Bartlett G, Abrahamowicz M, Grad R, Sylvestre MP, Tamplyn R (2009) Association between risk factors for injurious falls and new benzodiazepine prescribing in elderly persons. BMC Fam Pract 6: 10, 1

29. Rikala M, Korhonen MJ, Sulkava R, Hartikainen S (2010) The effects of medication assessment on psychotropic drug use in the community-dwelling elderly. Int Psychogeriatr 14: 1-12 (Epub ahead of print)

30. Folstein MF, Folstein SE, McHugh PR (1975) "Mini-Mental State”. A practical method for grading the cognitive state of patients for the clinician. J Psychiatr Res 12: $189-198$

31. Sheikh JI, Yesavage JA (1986) Geriatric depression scale (GDS): recent evidence and development of a shorter version. Clin gerontol 5:165-173

32. Lawton MP, Brody EM (1969) Assessment of older people: self-maintaining and instrumental activities of daily living. Gerontologist 9: 179-186

33. WHO Collaborating Centre for Drug Statistics Methodology (2009) Guidelines for ATC classification and DDD assignment 2010, Oslo. http://www.whocc.no/filearchive/publications/2010guidelines.pdf. Accessed 4 January 2011

34. McIntosh A, Cohen A, Turnbull N, et al (2004) Clinical Guidelines and Evidence Review for Panic Disorder and Generalised Anxiety Disorder. Sheffield: University of Sheffield/London: National Collaborating Centre for Primary Care. 

http://www.nice.org.uk/nicemedia/live/10960/29636/29636.pdf. Accessed 4 January 2011

35. American Psychiatric Association (2007) Practice guideline for the treatment of patients with obsessive-compulsive disorder. Arlington, VA: American Psychiatric Association. http://www.psychiatryonline.com/pracGuide/loadGuidelinePdf.aspx?file $=$ OCDPracticeGuidelineFinal05-04-07. Accessed 4 January 2011

36. Bartlett G, Abrahamowicz M, Tamblyn R, Grad R, Capek R, du Berger R (2004) Longitudinal patterns of new Benzodiazepine use in the elderly. Pharmacoepidemiol Drug Saf 13: 669-682

37. Saastamoinen L, Enlund H, Klaukka T (2008) Repeat prescribing in primary care: a prescription study. Pharm World Sci 30: 605-609

38. Iliffe S, Curran HV, Collins R, Yuen Kee SC, Fletcher S, Woods B (2004) Attitudes to long-term use of benzodiazepine hypnotics by older people in general practice: findings from interviews with service users and providers. Aging Ment Health 8: 242248

39. Cook JM, Biyanova T, Masci C, Coyne JC (2007) Older patient perspectives on longterm anxiolytic benzodiazepine use and discontinuation: A qualitative study. J Gen Intern Med 22: 1094-1100

40. Dickinson R, Knapp P, House AO et al (2010) Long-term prescribing of antidepressants in the older population: a qualitative study. Br J Gen Pract 60: 144155

41. Cook JM, Marshall R, Masci C, Coyne JC (2007) Physicians' perspectives on prescribing benzodiazepines for older adults: a qualitative study. J Gen Intern Med 22: 303-307 
1 42. Rikala M, Hartikainen S, Sulkava R, Korhonen MJ (2010) Validity of the Finnish Prescription Register for measuring psychotropic drug exposures among elderly Finns: a population-based intervention study. Drugs Aging 27: 337-349

43. Dekker FW, de Mutsert R, van Dijk PC, Zoccali C, Jager KJ (2008) Survival analysis: time-dependent effects and time-varying risk factors. Kidney Int 74: 994-997

6 
Table 1. Characteristics of community-dwelling users $(n=269)$ and nonusers $(n=431)$ of psychotropic drugs at baseline

\begin{tabular}{llccc}
\hline & & Users & Nonusers & $\mathbf{p}^{*}$ \\
CHARACTERISTICS & & $\mathrm{n}=269$ & $\mathrm{n}=431$ & \\
\hline Gender & & & & \\
Age (years) & mean (SD) $(\mathrm{n}, \%)$ & $213(79)$ & $273(63)$ & 0.000 \\
Living alone & yes (n, \%) & $81.7(4.8)$ & $80.2(4.4)$ & 0.000 \\
Years of education & $0-6(\mathrm{n}, \%)$ & $174(65)$ & $228(53)$ & 0.002 \\
GDS15 (0-15) & mean (SD) & $127(49)$ & $215(51)$ & 0.594 \\
MMSE (0-30) & $\leq 24(\mathrm{n}, \%)$ & $2.3(2.2)$ & $1.3(1.6)$ & 0.000 \\
IADL (0-8) & $\leq 6(\mathrm{n}, \%)$ & $76(29)$ & $94(22)$ & 0.044 \\
Number of visits to physician & $\geq 6(\mathrm{n}, \%)$ & $114(43)$ & $128(30)$ & 0.000 \\
Self-rated health & moderate or poor (n, \%) & $177(66)$ & $220(51)$ & 0.000 \\
Self-rated life satisfaction & moderate or poor (n, \%) & $184(69)$ & $250(58)$ & 0.005 \\
Number of non-psychotropic drugs & $\geq 9(\mathrm{n}, \%)$ & $72(27)$ & $56(13)$ & 0.000 \\
Number of psychotropic drugs & $\geq 2(\mathrm{n}, \%)$ & $76(28)$ & 0 & 0.043 \\
Pattern of psychotropic drug use & regular (n, \%) & $183(68)$ & 0 & \\
& & $59(22)$ & $69(16)$ & \\
\hline
\end{tabular}

\footnotetext{
* Pearson's $\chi^{2}$-test for category variables and Mann-Whitney U test for continuous variables

GDS15=Geriatric Depression Scale, MMSE=Mini-Mental State Examination, IADL=Instrumental Activities of Daily Living

Missing data: years of education ( $\mathrm{n}=18)$, GDS15 ( $\mathrm{n}=11)$, MMSE ( $\mathrm{n}=6$ ), IADL ( $\mathrm{n}=13$ ), number of visits to physician $(n=10)$, self-rated health $(n=2)$, self-rated life satisfaction $(n=2)$
} 
Table 2. Psychotropic drug use over a 3-year period in the community-dwelling baseline users $(n=269)$ and nonusers $(n=431)$

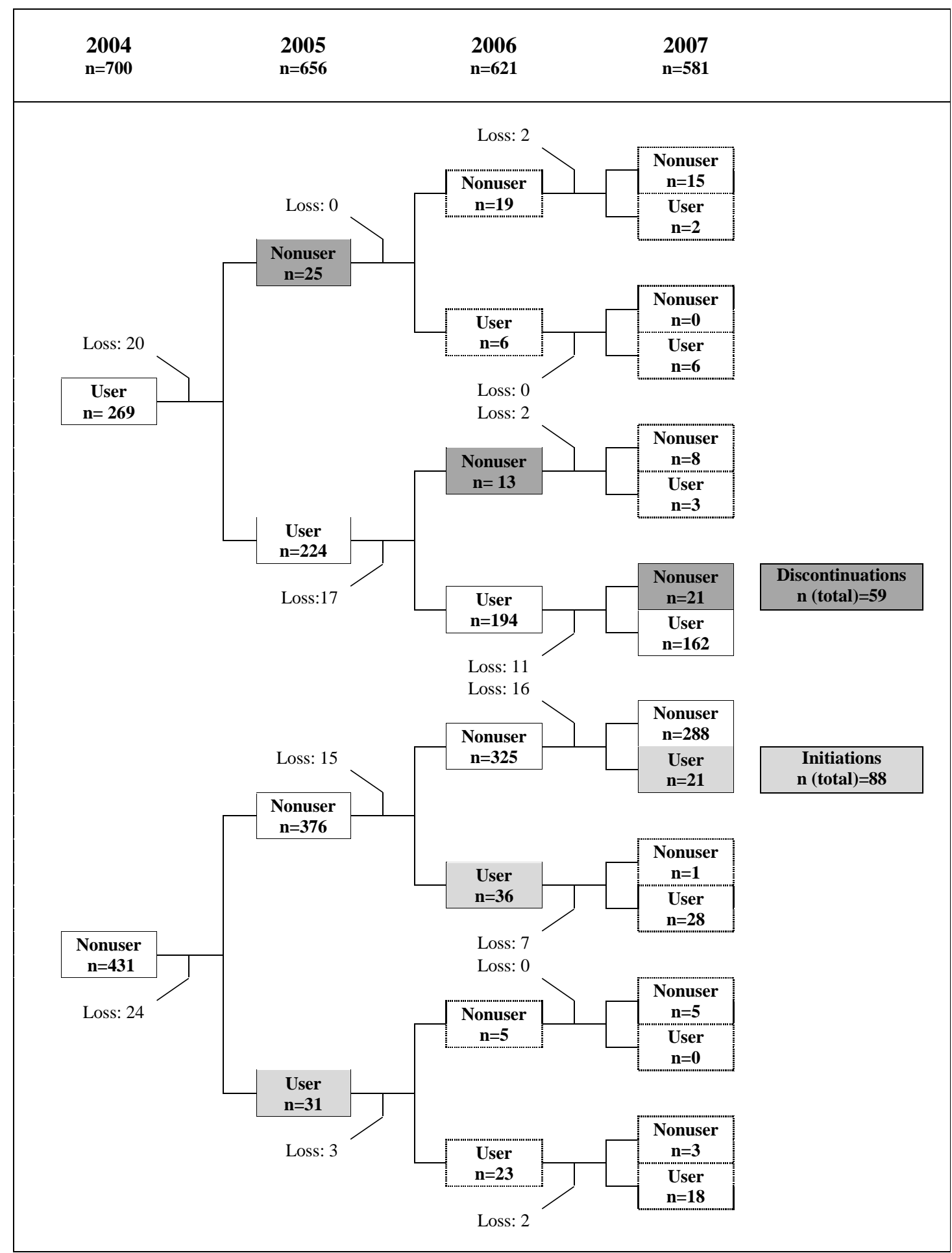

Loss=Lost to follow-up because of death, refusal, moving or not being able to contact 
Table 3. Antipsychotic, antidepressant and benzodiazepine use over a 3-year period in the community-dwelling baseline users and nonusers

Antipsychotics

n $(\%)$

40

83
Discontinued use

$14(35)$

17 (43)

9

660

617

Initiated use

$44(7)$

$512(78)$

104

32 (39)

$42(51)$

9

$62(10)$

Remained as nonuser

Loss to follow-up*
$453(73)$

102
219

481

$81(17)$

Benzodiazepines

n (\%)

59 (27)

$121(55)$

39

339 (70)

61

\footnotetext{
* Lost to follow-up because of death, refusal, moving or not being able to contact
} 
Table 4. Characteristics associated with persistent use of psychotropic drugs (event: discontinuation) in community-dwelling baseline users $(n=269)$

\begin{tabular}{|c|c|c|c|c|c|c|}
\hline \multirow[t]{2}{*}{ Characteristics } & & \multirow[b]{2}{*}{$\mathbf{n}$} & \multicolumn{2}{|c|}{ Crude* } & \multicolumn{2}{|c|}{ Adjusted $* *$} \\
\hline & & & HR & $95 \%$ CI & HR & $95 \% \mathrm{CI}$ \\
\hline \multirow[t]{2}{*}{ Gender } & men & 56 & 1.00 & & 1.00 & \\
\hline & women & 213 & 0.94 & $0.51-1.74$ & 0.68 & $0.32-1.45$ \\
\hline Age & per year & 269 & 0.95 & $0.90-1.01$ & 0.92 & $0.86-0.99$ \\
\hline \multirow[t]{2}{*}{ Living alone } & no & 95 & 1.00 & & 1.00 & \\
\hline & yes & 174 & 1.29 & $0.74-2.24$ & 1.84 & $0.97-3.51$ \\
\hline \multirow[t]{2}{*}{ Years of education } & $\geq 7$ & 133 & 1.00 & & 1.00 & \\
\hline & $0-6$ & 127 & 1.12 & $0.67-1.87$ & 1.74 & $0.96-3.13$ \\
\hline GDS15 & per score $(0-15)$ & 262 & 0.85 & $0.74-0.99$ & 0.95 & $0.81-1.11$ \\
\hline \multirow[t]{2}{*}{ MMSE } & $25-30$ & 189 & 1.00 & & 1.00 & \\
\hline & $\leq 24$ & 76 & 0.72 & $0.39-1.34$ & 1.12 & $0.50-2.50$ \\
\hline \multirow[t]{2}{*}{ IADL } & $7-8$ & 149 & 1.00 & & 1.00 & \\
\hline & $\leq 6$ & 114 & 0.75 & $0.44-1.29$ & 1.05 & $0.50-2.21$ \\
\hline \multirow[t]{2}{*}{ Number of visits to physician } & $0-5$ & 205 & 1.00 & & 1.00 & \\
\hline & $\geq 6$ & 59 & 1.41 & $0.80-2.48$ & 1.40 & $0.77-2.55$ \\
\hline Self-rated health & good & 91 & 1.00 & & 1.00 & \\
\hline
\end{tabular}


moderate or poor

177

1.47

$0.83-2.62$

1.92

1.01-3.68

\begin{tabular}{|c|c|c|c|c|c|c|}
\hline \multirow[t]{2}{*}{ Self-rated life satisfaction } & excellent & 84 & 1.00 & & 1.00 & \\
\hline & moderate or poor & 184 & 0.80 & $0.46-1.39$ & 0.64 & $0.35-1.17$ \\
\hline \multirow[t]{2}{*}{ Number of non-psychotropic drugs } & $0-8$ & 197 & 1.00 & & 1.00 & \\
\hline & $\geq 9$ & 72 & 1.21 & $0.69-2.12$ & 0.99 & $0.52-1.87$ \\
\hline \multirow[t]{2}{*}{ Number of psychotropic drugs } & 1 & 193 & 1.00 & & 1.00 & \\
\hline & $\geq 2$ & 76 & 0.26 & $0.11-0.60$ & 0.26 & $0.10-0.70$ \\
\hline \multirow[t]{2}{*}{ Pattern of psychotropic drug use } & as needed & 86 & 1.00 & & 1.00 & \\
\hline & regular & 183 & 0.39 & $0.23-0.65$ & 0.47 & $0.26-0.84$ \\
\hline
\end{tabular}

$\mathrm{HR}=$ hazard ratio, $\mathrm{CI}=$ Confidence Interval, GDS15=Geriatric Depression Scale, MMSE=Mini-Mental State Examination, IADL=Instrumental Activities of Daily Living

* Cox proportional-hazards regression (adjusted for group assignment, participants with missing data are excluded).

** Cox proportional-hazards regression (adjusted for group assignment and the other variables listed in the Table 2. Participants missing data on the chosen variables $(n=23)$ are excluded from the analysis except for GDS15 scores, the values for which were imputed with the mean value for the whole study population). 
Table 5. Characteristics associated with incident use of psychotropic drugs in communitydwelling baseline nonusers $(n=431)$

\begin{tabular}{|c|c|c|c|c|c|c|}
\hline \multirow[t]{2}{*}{ Characteristics } & & \multirow[b]{2}{*}{$\mathbf{n}$} & \multicolumn{2}{|c|}{ Crude* } & \multicolumn{2}{|c|}{ Adjusted $* *$} \\
\hline & & & HR & $95 \%$ CI & HR & $95 \%$ CI \\
\hline \multirow[t]{2}{*}{ Gender } & men & 158 & 1.00 & & & \\
\hline & women & 273 & 1.35 & $0.85-2.13$ & 1.15 & $0.67-1.97$ \\
\hline Age & per year & 431 & 1.04 & $0.99-1.08$ & 1.01 & $0.96-1.06$ \\
\hline \multirow[t]{2}{*}{ Living alone } & no & 203 & 1.00 & & 1.00 & \\
\hline & yes & 228 & 1.49 & $0.97-2.30$ & 1.29 & $0.80-2.08$ \\
\hline \multirow[t]{2}{*}{ Years of education } & $\geq 7$ & 207 & 1.00 & & 1.00 & \\
\hline & $0-6$ & 215 & 1.11 & $0.73-1.70$ & 0.96 & $0.61-1.52$ \\
\hline GDS15 & per score $(0-15)$ & 427 & 1.32 & $1.20-1.44$ & 1.22 & $1.08-1.37$ \\
\hline \multirow[t]{2}{*}{ MMSE } & $25-30$ & 335 & 1.00 & & 1.00 & \\
\hline & $\leq 24$ & 94 & 3.09 & $2.02-4.73$ & 2.49 & $1.49-4.16$ \\
\hline \multirow[t]{2}{*}{ IADL } & $7-8$ & 296 & 1.00 & & 1.00 & \\
\hline & $\leq 6$ & 128 & 2.14 & 1.39-3.28 & 1.29 & $0.75-2.22$ \\
\hline \multirow[t]{2}{*}{ Number of visits to physician } & $0-5$ & 357 & 1.00 & & 1.00 & \\
\hline & $\geq 6$ & 69 & 2.03 & $1.26-3.25$ & 1.94 & $1.16-3.25$ \\
\hline Self-rated health & good & 210 & 1.00 & & 1.00 & \\
\hline
\end{tabular}


Self-rated life satisfaction

Number of non-psychotropic drugs good

moderate or poor

0-8

$\geq 9$
$180 \quad 1.00$

$250 \quad 2.33$

$1.43-3.78$

1.00

1.82

1.04-3.17

$375 \quad 1.00$

1.00

$\begin{array}{lllll}56 & \mathbf{2 . 3 0} & \mathbf{1 . 4 0}-\mathbf{3 . 7 4} & 1.41 & 0.81-2.45\end{array}$

$\mathrm{HR}=$ hazard ratio, $\mathrm{CI}=$ Confidence Interval, GDS15=Geriatric Depression Scale, MMSE=Mini-Mental State Examination, IADL=Instrumental Activities of Daily Living

* Cox proportional-hazards regression (adjusted for group assignment, participants with missing data are excluded).

** Cox proportional-hazards regression (adjusted for group assignment and the other variables listed in the Table 3. Participants missing data on the chosen variables $(n=23)$ are excluded from the analysis except for GDS15 scores, the values for which were imputed with the mean value for the whole study population). 